\title{
Huffmanela sp. (Nematoda: Trichosomoididae: Huffmanelinae) encountered in the whitecheek shark (Carcharhinus dussumieri) in the Arabian Gulf
}

\author{
M. M. ATTIA ${ }^{1}$, M. M. IBRAHIM ${ }^{2,3}$, M. A. MAHMOUD ${ }^{4}$, M. N. S. AL-SAB| $\left.\right|^{5, *}$ \\ 'Department of Parasitology, Faculty of Veterinary Medicine, Cairo University, 12211, Giza, Egypt, \\ E-mail: marwaattia.vetpara@cu.edu.eg, marwaattia.vetpara@yahoo.com; ${ }^{2 D e p a r t m e n t ~ o f ~ P a t h o l o g y, ~ A n i m a l ~ H e a l t h ~ R e s e a r c h ~ I n s t i t u t e, ~}$ \\ Dokki, Giza, 12618, Egypt, E-mail: dr_mustafa_m@yahoo.com; ${ }^{3}$ Ministry of Agriculture, Fish Welfare Branch, El-Jubail Province, \\ Saudi Arabia; ${ }^{4}$ Department of Pathology, Faculty of Veterinary Medicine, Cairo University, Giza, 12211, Egypt, \\ E-mail:mahmoudaly@cu.edu.eg; ${ }^{5, *}$ Department of Microbiology, College of Veterinary Medicine, King Faisal University, \\ P.O. Box: 400, Al-Ahsa, 31982, Saudi Arabia, E-mail: malsabi@kfu.edu.sa
}

Article info

Received December 23, 2020

Accepted July 12, 2021

\begin{abstract}
Summary
Veterinary inspection of fish caught at the western side of the Arabian Gulf off the shore of Saudi Arabia in 2017 revealed abnormal irregular zigzag black lines in the skins of 135 out of 1500 (prevalence $=9 \%$ ) whitecheek sharks (Carcharhinus dussumieri). These lesions have been noticed in the dorsal and ventral part of the head near the snout and around the eyes, as well as in the skin of the pectoral fins. The parasitological, pathological and ultramorphological aspects of the sampled fish were studied using a light microscope, as well as scanning and transmission electron microscopes. Trichosomoidid-type eggs identified as Huffmanela sp. were found in the superficial layer of the skin. The mature eggs containing larvae $(n=75)$ were ellipsoidal or spindle-shaped, smooth-shelled, amber-brown to dark brown or even black in colour. The width of the eggs ranged from 34 to $49 \mu \mathrm{m}$ with lengths ranging from 95 to $107 \mu \mathrm{m}$. The polar plugs of the immature eggs were slightly protruding, whereas mature eggs had clearly protruding polar plugs. The width of the polar plugs ranged from $4.5-9.5 \mu \mathrm{m}$. The shells of the eggs were smooth and there was a thin layer seen near the polar areas. The infected skin exhibited desquamated epithelium, with inflammatory cell aggregations and melanophores in the debris. The underlying musculatures of the skin were free from any eggs, but showed mild pathological changes, including congestion of blood vessels, haemorrhages and oedema. The prevalence of infection showed seasonality, peaking significantly in the spring $(18.18 \%)$, with comparable prevalence rates in winter and summer $(9.43 \%$ and $8.57 \%$, respectively). However, infections dropped signifi cantly during the autumn months (3.75\%). It is believed that this is the first study reporting the presence of Huffmanela sp. in whitecheek sharks at El-Jubail Province, Saudi Arabia, Arabian Gulf.
\end{abstract}

Keywords: Huffmanela; Egg morphology; shark; skin parasite; prevalence

\section{Introduction}

Huffmanela spp. are nematode parasites affecting elasmobranch species, including sharks (Pollerspöck, 2012). The genus Huffmanela Moravec, 1987 comprises 21 valid species (Ruiz \& Bul- lard, 2013; Ruiz et al., 2013; Justine \& Iwaki, 2014; Ramos et al., 2019), diagnosed by the size and shape of their eggs, taking into consideration host range and site of infection (Bullard et al., 2012; Ruiz et al., 2013; Justine \& Iwaki, 2014; Attia et al., 2021). This histozoic nematode deposits its eggs in specific organs, induc-

\footnotetext{
$\overline{\text { * }- \text { corresponding author }}$
} 
ing characteristic pathological lesions, easily seen with the naked eye (Moravec etal., 1998; Moravec \& Garibaldi, 2000; Bullard et al., 2012). Theseegg depositions produce dark spots and lines, rendering thesefish unmarketable, hence leading to an economic consequenceof consumer refusal of fish (Worsham et al., 2016). Huffmanelaschouteni infections have been recorded in humans, but these generally are considered as passage of eggs after consumption of infected fish, with no obvious clinical signs (Gallego et al., 1993). The aim of this study was to identify the species of Huffmanela thatinduced the pathological grey to black-grey irregular lines in the skin of whitecheek sharks (Carcharhinus dussumieri) at El-JubailProvince, at the eastern shore of Saudi Arabia. We reported theinfections for the entirety of 2017 and performed detailed parasitological, pathological and ultramorphological studies using light, scanning and transmission electron microscopes.

\section{Materials and Methods}

\section{Sample collection}

During 2017, regular veterinary inspection of the health condition of fish and sharks took place at the commercial harbour at two landing stations, a fish auction house and one fish market in El-Jubail city, located at the west side of the Arabian Gulf in the Eastern region of Saudi Arabia. During that year, 1500 whitecheek shark specimens were examined (Carcharhinus dussumieri Valenciennes, 1839, Family: Carcharhinidae, locally known in Arabic as Jarjur). The sharks were clinically examined for any abnormal external skin lesions and/or discoloration resembling those caused by Huffmanela spp.; the internal organs were then inspected for any pathological lesions pertaining to the presence or migration routes of adult nematodes or possible depositions

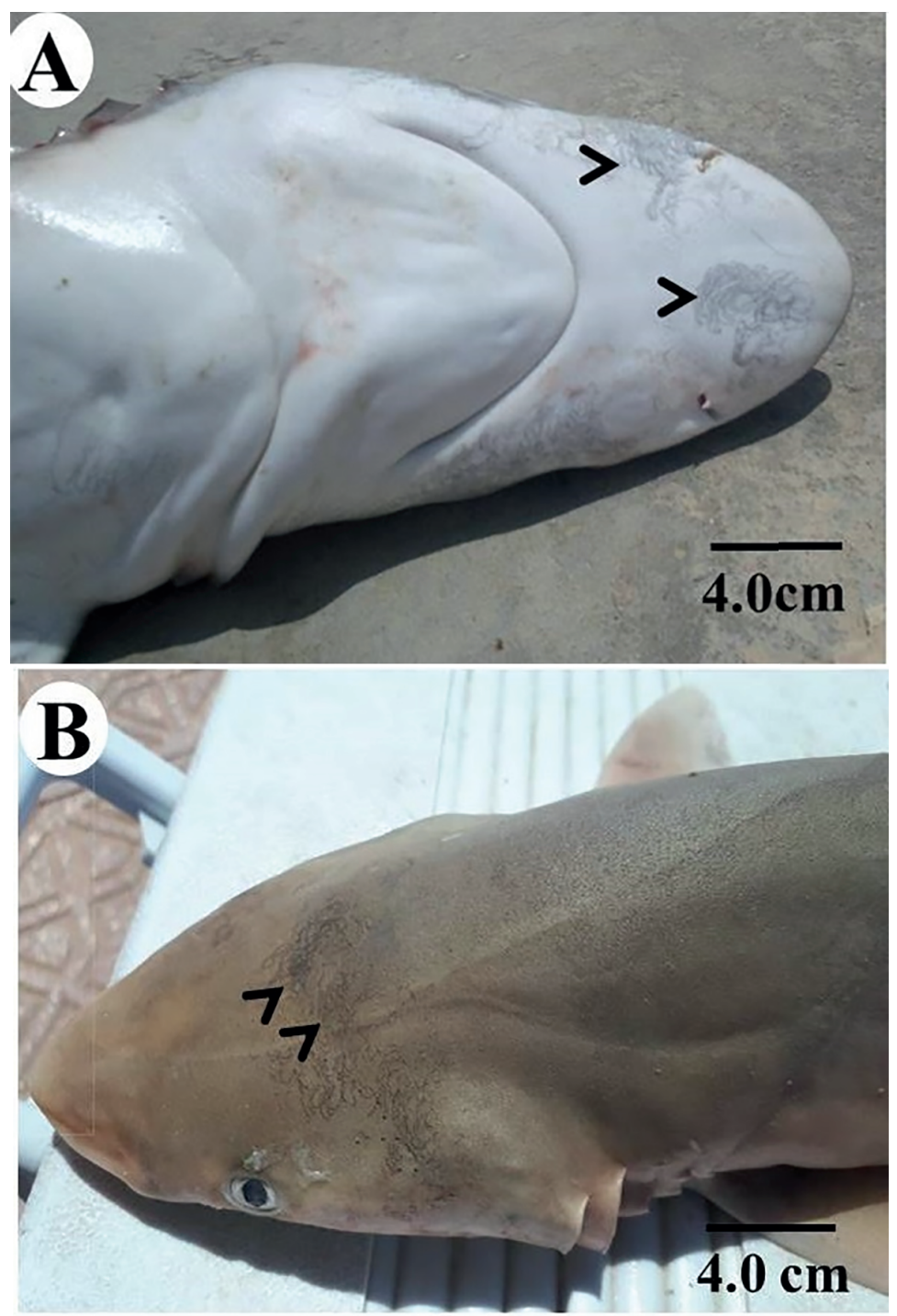

Fig. 1. Gross external lesions on skins of whitecheek shark (Carcharhinus dussumieri) showing the presence of (A) Black irregular lines withvery minute black spots in the ventral aspect of head region and near the snout. (B) Prominent black irregular lines in the dorsal region of the head. 

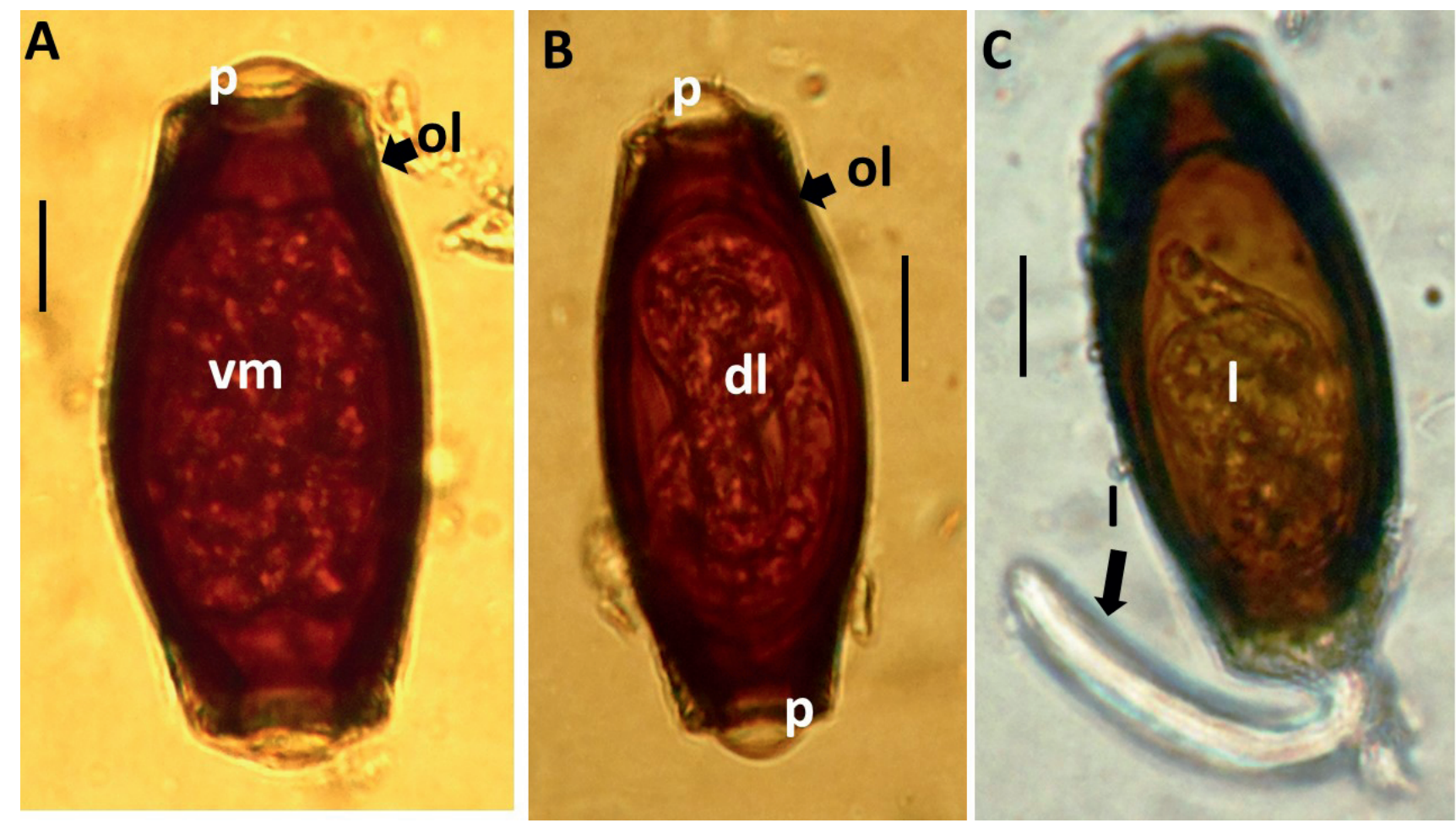

Fig. 2. Eggs of Huffmanela sp. isolated from skins of whitecheek shark (Carcharhinus dussumieri) and examined using light microscope. (A) Immature stage of the eggs, stage 1, showing dark brown eggshell, slightly protruding polar plug (p), vitelline mass (vm), and outer shell layer (ol). (B) Mature eggs, stage 2, showing the brownshelled egg containing developing larva (dl), markedly protruding polar plugs (p), and outer shell layer (ol). (C) Mature eggs, stage 2, showing fully developed brownshelled egg containing an outer layer, missing polar plugs, and ready to hatch a fully developed larva (I). Scale bar in A, B, and C $=25 \mu \mathrm{m}$.

of eggs. Skin lesions resembling those caused by Huffmanela spp. were typically having abnormalgreyish to black irregular lines. Infected fish with such lesions were totally condemned due to aesthetic reasons. Skin lesions were fixed for both pathological and parasitological studies; one part was kept in formalin (10\%) and another in ethyl alcohol $(70 \%)$, respectively.

\section{Parasitological examination}

The affected skin specimens in ethyl alcohol (70 \%) were sent to the Parasitology Department at the Faculty of Veterinary Medicine, Cairo University, Egypt, for further examination. Skin scrapings were performed from the lesions and were examined under a stereomicroscope. The scrapings were placed on wet-mounted slides without coverslip pressure to investigate the presence of eggs and/or larvae. Once eggs were found, the mounted slides were subjected to further examination using a light microscope (Olympus AX70 connected to a Nikon camera). The eggs $(n=100)$ were photographed, and measurements were reported in micrometres $(\mu \mathrm{m})$. All measurements were expressed as (minimum-maximum; mean and \pm Standard Deviation (SD)). Huffmanela sp. was identified after describing the features of the mature, brown-shelled eggs that contained developing larvae as previously described (Bullard et al., 2012; Ruiz et al., 2013; Justine \& Iwaki, 2014).

\section{Histopathological examination}

Affected skin samples fixed in $10 \%$ neutral buffered formalin were sent to Pathology Department at the Faculty of Veterinary Medicine, Cairo University, Egypt, for histopathological examination. The fixed specimens were washed in water, dehydrated in ascending concentrations of ethanol (50\% to $100 \%$; each for durations of $20 \mathrm{~min}$ ), cleared in xylene and then embedded in paraffin wax. Standard histological protocols and sectioning $(4-5 \mu \mathrm{m})$ were performed and tissue sections on the slides were stained with Haematoxylin and Eosin (H\&E) (Roberts, 2012).

\section{Scanning electron microscope examination of parasitic eggs (SEM)}

The samples fixed in $10 \%$ buffered formalin were prepared according to Bullard et al. (2012), with minor changes. Briefly, different parts of the infected skin were washed several times using phosphate buffer saline (pH 7.2), then fixed in $2.5 \%$ glutaraldehyde at $4^{\circ} \mathrm{C}$ for 24 hours. The samples were dehydrated by passing them through serial ascending concentrations of ethanol ( $50 \%$ to $100 \%$; each for a duration of 20 minutes). The specimens were then dehydrated on filter paper (Whatman Grade 1, Cat. No. 1001110); complete dryness occurred in a $\mathrm{CO}_{2}$ critical point drier (Autosamdri-815, Germany). The samples were then glued onto 
stubs, coated with $20 \mathrm{~nm}$ gold in a sputter coater (Spi-Module Sputter Coater, UK), examined and photographed using a JSM 5200 electron probe microanalyzer (JEOL, Japan) at the College of Agriculture, Cairo University, Egypt.

\section{Transmission electron microscope examination (TEM)}

Specimens were prepared according to the previously described procedures of Zdarska et al. (2001). In short, skin samples were rinsed in saline, re-fixed in $2.5 \%$ glutaraldehyde, and soaked in $0.1 \mathrm{M}$ cacodylate buffer $(\mathrm{pH} 7.2)$ at $4^{\circ} \mathrm{C}$ overnight, fixed in $1 \%$ osmium tetroxide at $4^{\circ} \mathrm{C}$ for 24 hours, dehydrated in an ethyl alcohol series (50\% to $100 \%$; each series took $24 \mathrm{hrs}$.), then embedded in epoxy resin. Microtome sections of $500-100 \mu m$ thickness were prepared using a Leica ultracut (UCT ultramicrotome). The thin sections were stained with toluidine blue (1X), then examined using a Leica camera (ICC50HD). Ultrathin sections of approximately 75 - 90nm thickness were prepared and stained with uranyl acetate and lead citrate, then examined by transmission electron microscope (JEOL, JEM-1400 TEM) at the College of Agriculture, Cairo University.

\section{Statistical analysis}

Summaries and statistics were done using Excel ${ }^{T M}$ (Office 2003), including means and standard deviations (SD). A $95 \%$ confidence interval $(\mathrm{Cl})$ was calculated, with no continuity correction according to Newcombe (1998). Chi-square (X2) calculations were inferred using $2 \times 2$ contingency tables according to Yates (1934). Results with $p$ values below 0.05 were considered significant.

\section{Ethical Approval and/or Informed Consent}

This study has been approved by the Institutional Animal Care and Use Committee, Faculty of Veterinary Medicine, Cairo University, Egypt (Vet. CU. IACUC, approval No. Vet-cu 02122019101).
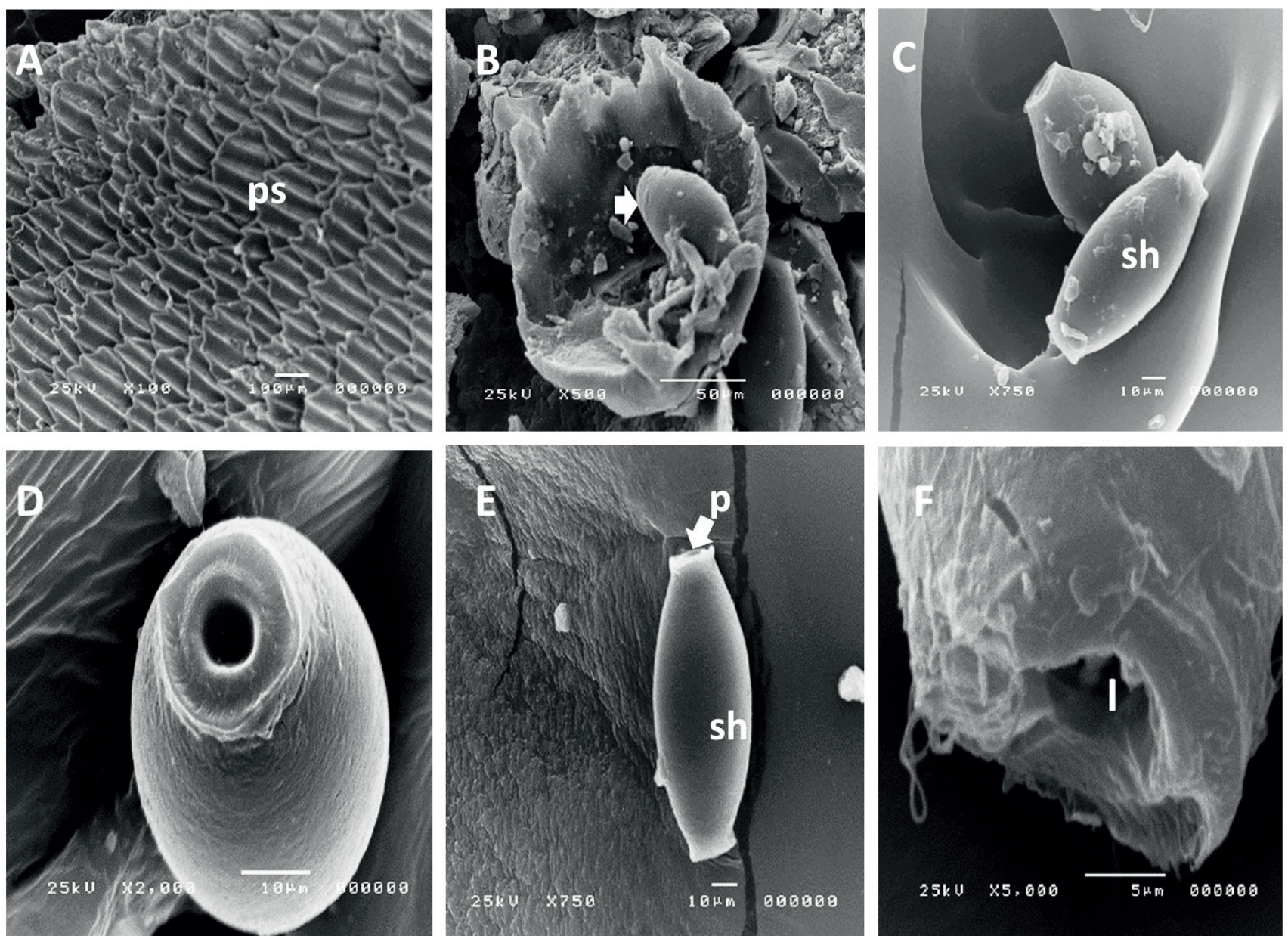

Fig. 3. Scanning electron micrographs of Huffmanela sp. eggs (Nematoda, Trichosomoididae, Huffmanelinae) recovered from whitecheek shark (Carcharhinus dussumieri). (A) Infected skin of shark showing crowns of placoid scales (ps). (B) Skin scraping from a shark showing the nematode egg (arrows).

$(C, D$, and E) Eggs recovered from skin scraping of a shark showing smooth shell (sh) and slightly protruding plug (p). (F) Posterior end of Huffmanela sp. eggs, showing ready to hatch larvae (I). 


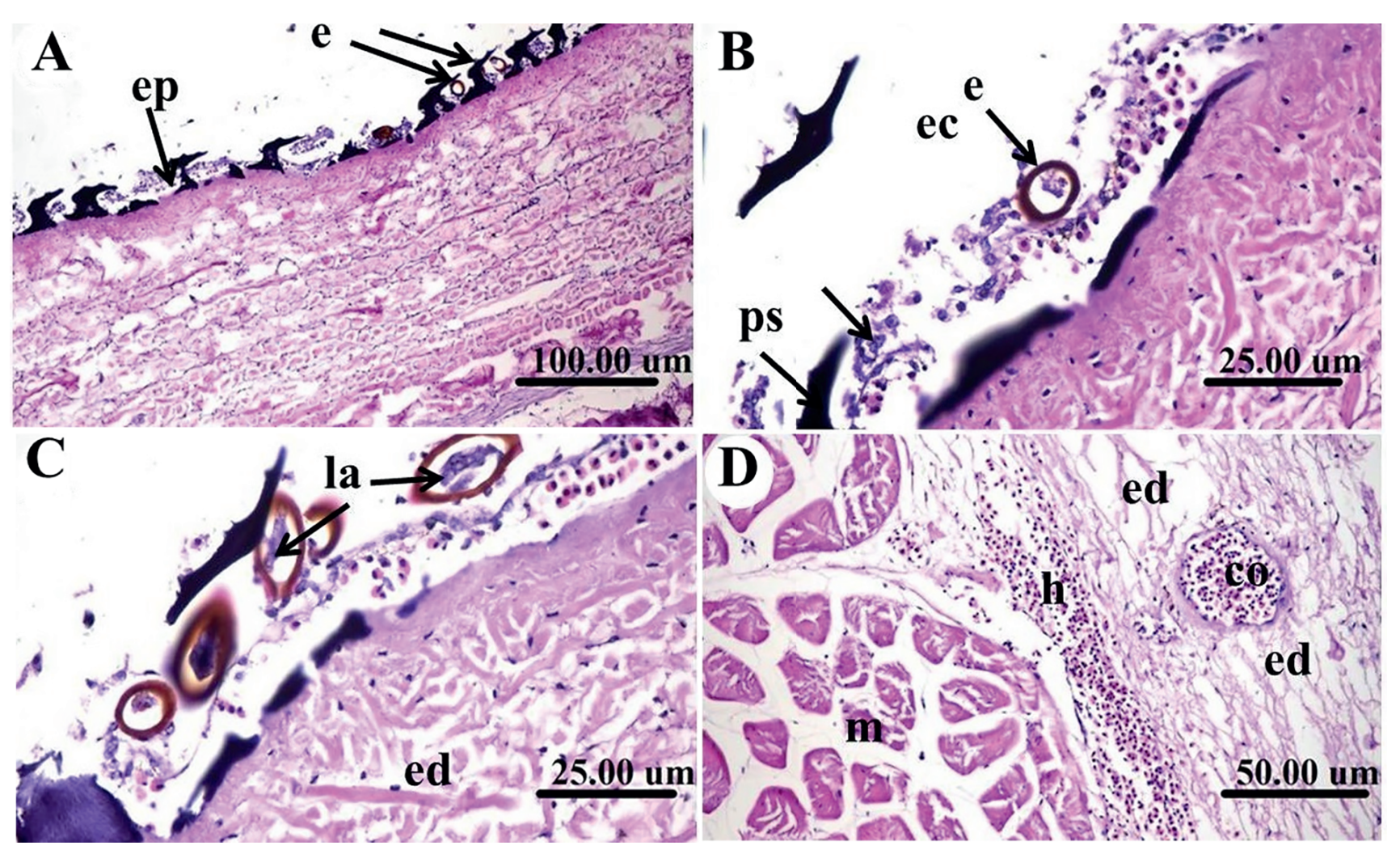

Fig. 4. Histopathology of skins of whitecheek shark (Carcharhinus dussumieri) showing the pathology induced by the presence of eggs of Huffmanela sp..(A) Apparently normal epidermal region (ep) and affected epidermis with multiple eggs (e) of Huffmanela sp. between the placoid scales. (B) Affected epidermis with eggs of Huffmanela sp. (e), desquamated epithelial cells (ec), and detached placoid scales (ps). (C) Multiple eggs of Huffmanela sp. containing developing larvae (la), desquamated epithelium and pyknotic nuclei in stratum laxum. (D) congested blood vessel (co), area of hemorrhage (h) and edema (ed) with no presence of parasitic eggs in the underlying musculature (m). (H\&E staining).

\section{Results}

\section{Gross and clinical examination}

Out of 1500 examined sharks, 135 specimens (overall prevalence of $9 \%$; $95 \% \mathrm{Cl}: 7.65$ - $10.55 \%$ ) showed colour abnormality in the skin, exhibited by irregular, fine black zigzag lines with minute black spots in the ventral (Fig. 1A) and dorsal parts of the head near the snout and around the eyes (Fig. 1B). The gross and clinical examinations of the internal visceral organs for all the sharks with skin infections did not reveal any signs or pathological lesions in the viscera.

\section{Parasitological examination}

Parasitological examination of the affected skin showed thousands of nematode parasite eggs. The eggs exhibited two stages in terms of development: 1) immature or less advanced egg stages that contained vitelline mass and 2) mature or advanced egg stages that contained developing larvae. Immature eggs (stage $1, n=$ 25) were ellipsoidal or spindle-shaped with slightly protruding polar plugs. Both the immature and mature eggs were yellow-brown to dark brown in colour and had a smooth shell, i.e. lacking spines, filaments or ridges (Fig. 2A, 2B, and $2 \mathrm{C}$ ). The width of the eggs ranged from $35-48 \mu \mathrm{m}(41 \pm 5)$, with lengths ranging from $92-110 \mu \mathrm{m}(99 \pm 5)$. The width of the polar plugs ranged from $6.6-11.5 \mu \mathrm{m}(9 \pm 2)$. The width of the vitelline mass ranged from $55-65 \mu \mathrm{m}(61 \pm 2)$; its length ranged from $35-38 \mu \mathrm{m}(36 \pm 1)$.

Mature eggs containing larvae (stage $2, n=75$ ) were ellipsoidal or spindle-shaped with markedly protruding polar plugs and had smooth shells, i.e. lacking spines, filaments or ridges (Fig. 2B and 2C). Their colour was amber-brown to dark brown; some were even black. The width of the eggs ranged from $34-49 \mu$ m (42 \pm 5) and the length ranged from $95-107 \mu \mathrm{m}(101 \pm 4)$. The polar plugs of the mature eggs were markedly protruding (Fig. 1B). The width of the polar plugs ranged from $4.5-9.5 \mu m(7 \pm 2)$. An outer shell layer can be seen near the poles of the eggs (Fig. 2B). No larvae were detected in the skin specimens, although some larvae hatched during preparation of the eggs for morphological examination (Fig. 2C).

\section{Scanning electron microscopy results}

Scanning electron micrographs showed the presence of parasitic eggs settling on and between the placoid scales of the skin of the infected sharks (Fig. 3A and 3B). These eggs had smooth shells, with no spines, filaments or ridges (Fig. 3B, 3C, 3D, and 

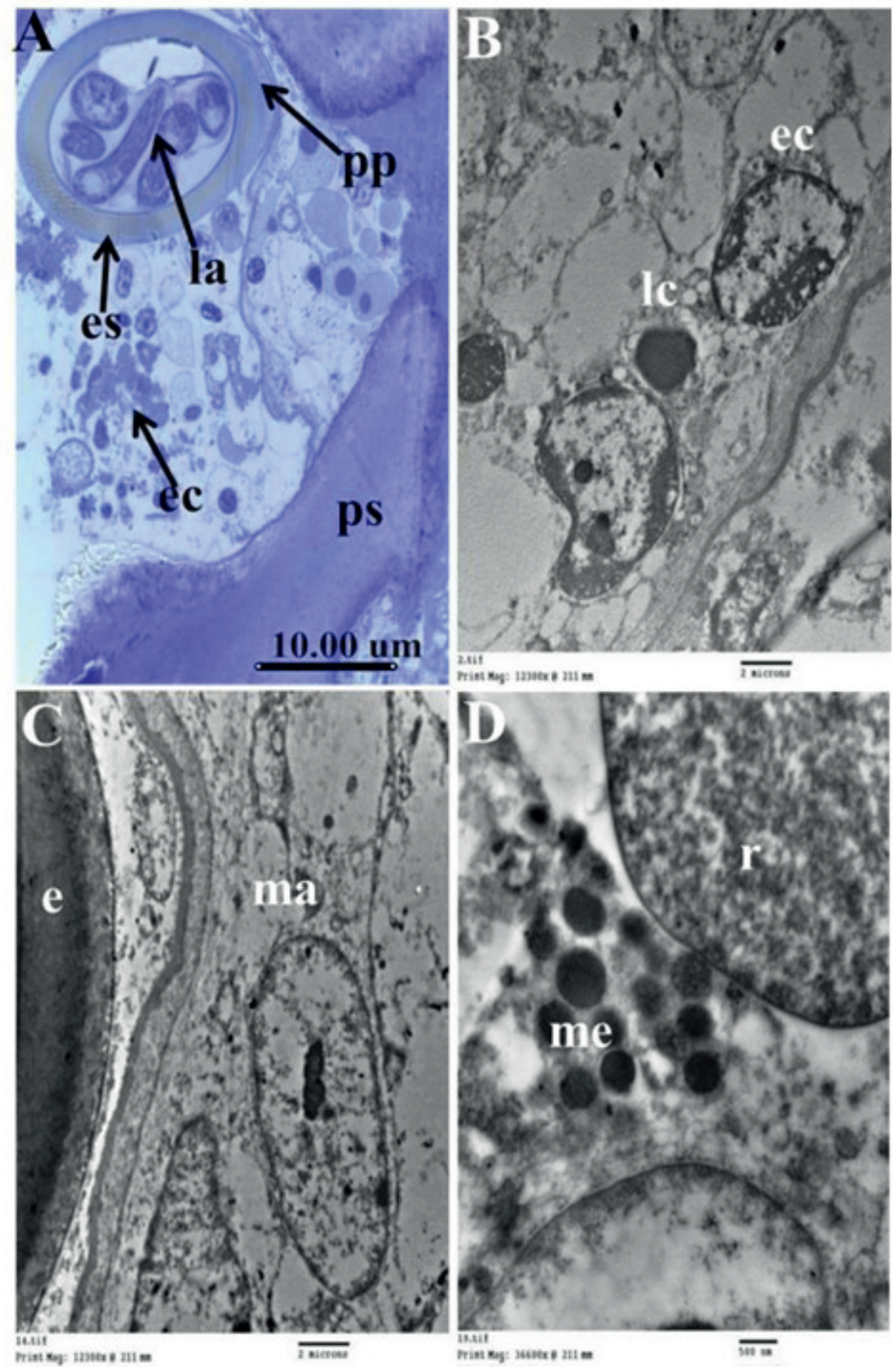

Fig. 5. Tansmission electron micrographs of semi-thin and ultra-thin sections of skin of whitecheek shark (Carcharhinus dussumieri) affected with egg of Huffmanela sp.. (A) Semi-thin image showing an egg in the epidermis with non-lamellated eggshell (es), with polar plugs (pp), the eggs were embedded between placoid scales (ps) and desquamated epithelial cells (ec). (B-D): Transmission electron micrographs showing (B) Epithelial cell (ec) and lymphocyte (Ic) in the affected area, (C) A parasitic egg (e) surrounded with macrophages (ma), and (D) Melanophores containing melanin pigments appearing near a red blood cell (r). Scale bar in $B$ and $C=2 \mu \mathrm{m}$, and in $D=500 \mathrm{~nm}$. 
3E). Several eggs were in stage 2, with larvae ready to hatch (Fig. 3F). Some eggs had slightly protruding polar plugs (Fig. 3E) but the lack of protruding plugs, in some eggs, can be associated with the method of preparing specimens for electron microscopy. The mature eggs carried expanded poles on both sides, forming a distinctive crownlike structure in the lateral view (Fig. 3C, 3D, and 3E).

Based on the previously published descriptions and illustrations of MacCallum (1925), Moravec (1987) and Bullard et al. (2012), we concluded that the eggs were typically of the trichosomoidid type and identified them as Huffmanela sp.

\section{Histopathological findings}

In the histopathological sections, the infected skin showed numerous parasitic eggs of Huffmanela sp. embedded between the placoid scales of the pectoral fins (Fig. 4A). The epidermis of these samples showed desquamated epithelial cells and detached placoid scales (Fig. 4B). The eggs in the histological sections con- tained developing larvae (Fig. 4C). The blood vessels were congested, and areas of haemorrhage, inflammation and oedema were common even without the presence of eggs in the underlying muscular layer of the skin (Fig. 4D). These pathological changes were confined to the skin of the infected sharks.

\section{Examination of Semi-thin \& Ultra-thin sections of the skin}

In the semi-thin sections, the Huffmanela sp. eggs embedded below and between the placoid scales had prominent polar plugs (Fig. 5A). The skins exhibited desquamated epithelium, with the presence of inflammatory cells and eggs containing developing larvae. In the ultra-thin sections examined using TEM, desquamated epithelial cells were observed, along with adjacent lymphocytes (Fig. 5B) and a few macrophage cells surrounding the Huffmanela eggs (Fig. 5C). The presence of melanophores containing melanin pigments near extravasated red blood cells was also observed (Fig. 5D).

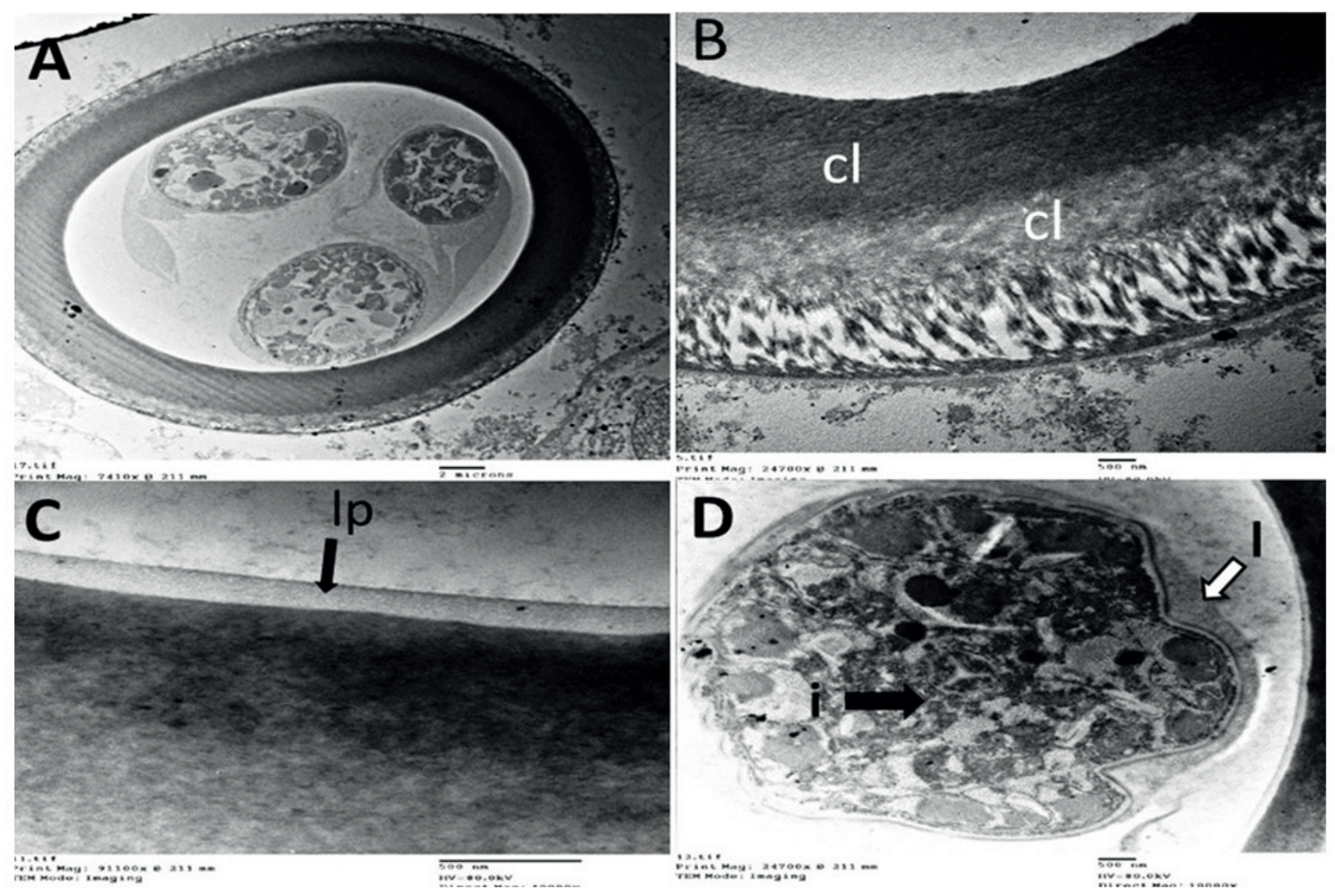

Fig. 6. Transmission electron micrographs of Huffmanela sp. eggs (Nematoda, Trichosomoididae, Huffmanelinae) recovered from skin scrapings from whitecheek shark (Carcharhinus dussumieri). (A) Cross section of eggs with mature larva. (B) Ultrastructure of eggs layers showing all parts of the eggshell. The vitelline layer (v) was thin and smooth and had no projections, spines, ridges or filaments. The chitinous layer (cl) had two different electron densities or parts identified as an external and an internal homogenous part that was not lamellated nor contained ridges. (C) Ultrastructure of eggs layers showing the presence of a third, thin lipid layer (Ip) that was translucent and homogeneous. (D) Higher magnification showing larva (I) inside the eggs with appearance of its intestine (i) and larval tissues. Scale bar in $A=2 \mu \mathrm{m}$; in $B, C$, and $D=500 \mathrm{~nm}$. 


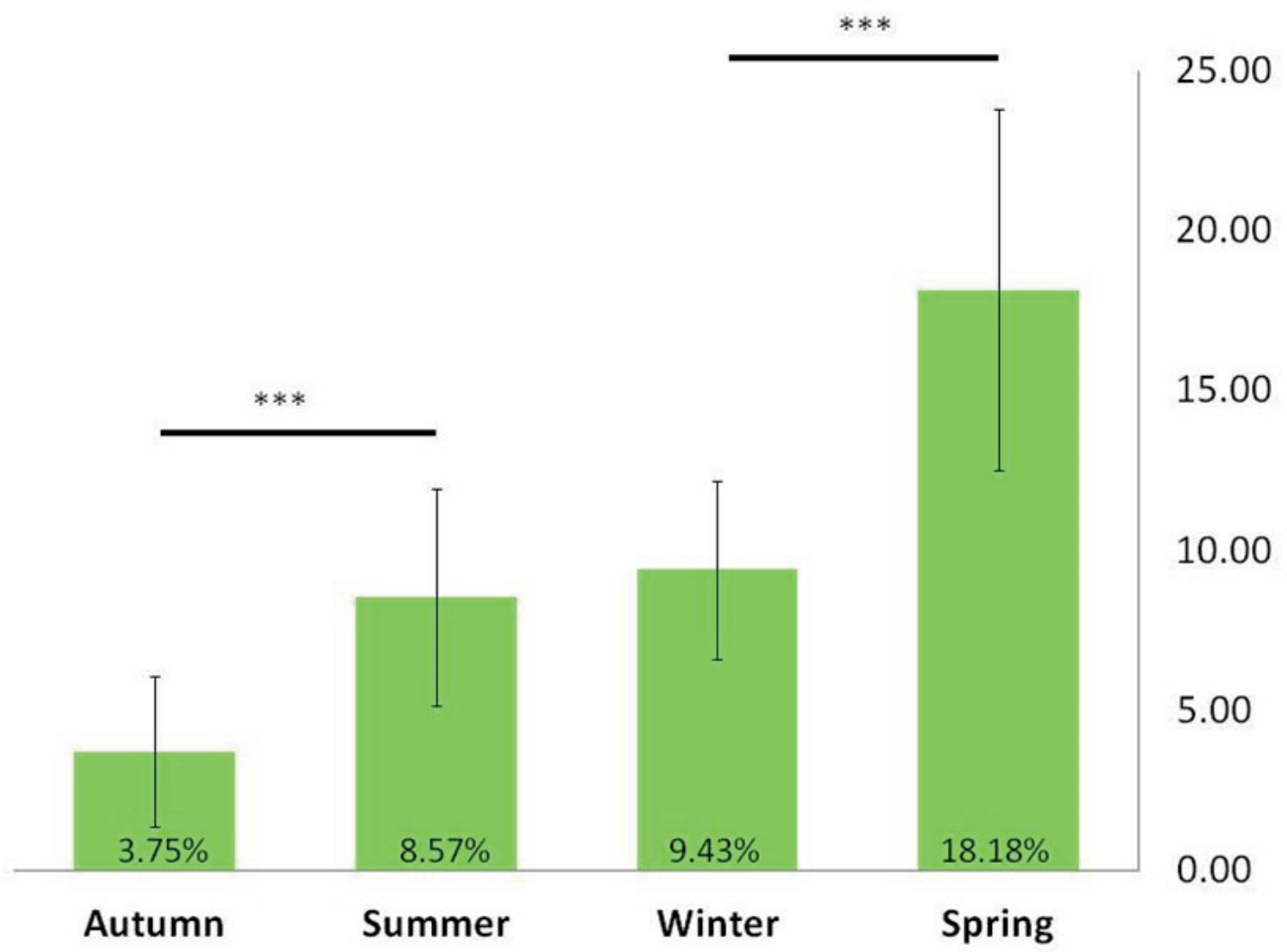

Fig. 7. Seasonal prevalence (\%) of Huffmanela sp. in whitecheek shark (Carcharhinus dussumieri) during 2017 in El-Jubail, Saudi Arabia. Black line with ${ }^{* * *}$ on top indicates statistical significant difference $(p$-value $<0.001)$ in prevalence rates between the two lined, adjacent seasons.

\section{TEM examination of the Huffmanela eggs}

The shells of the parasite eggs had thicknesses ranging from $1.5-2.2 \mu \mathrm{m}(2 \pm 0.3$; Fig. $6 \mathrm{~A})$. The ultra-morphological identification of the eggs using TEM revealed that the eggshells consisted of three layers (Fig. 6A and 6B). The first layer was an external vitelline layer that enveloped the entire egg; this layer consisted of network-like structures and was thin and smooth with no projections, spines, ridges or filaments. The second layer was chitinous in structure and consisted of two homogenous parts that were different in electron density, one external and another internal (Fig. $6 \mathrm{~B})$. The third was a thin, translucent and homogeneous lipid layer (Fig. 6C). Inside mature eggs, the larvae, surrounded by yolk material, were apparently coiled several times and their intestinal and muscular tissues could be seen (Fig. 6D).

\section{Prevalence}

There was no difference in overall prevalence between infected male and female sharks. Of the examined females $(n=954), 85$ were infected (overall prevalence of $8.99 \% ; 95 \% \mathrm{Cl}: \pm 1.66$; $7.33-10.98)$, whereas 50 of the examined males $(n=555)$ were infected (overall prevalence of $9.01 \% ; 95 \% \mathrm{Cl}: \pm 2.67$; 6.9 - 11.68). The average length of the sharks ranged from
$60-100 \mathrm{~cm}$ (Supplementary materials Figure S1), with weights ranging from $3.5-8.5 \mathrm{~kg}$.

Huffmanela infections showed seasonal differences in prevalence rates $(x 2=36.3081 ; p$-value $<0.00001 ;$ Fig. 7$)$. The occurrences peaked in the spring with a rate of $18.18 \%(40 / 220 ; \chi 2=11.2662$; $p$-value $=0.000789$; Yates correction is 10.453 with $p$-value $=$ $0.001224)$, followed by the winter with a prevalence rate of $9.43 \%$ (50/530). The prevalence rates were not significantly different between winter and summer; both had a rate of approximately $8.657 \%$ (30/350). However, the prevalence dropped significantly to a rate of $3.57 \%$ in autumn (15/400; $95 \% \mathrm{Cl} \pm 2.34 ; 2.29$ to $6.09 ; X^{2}=7.6938 ; p$-value $=0.005541$; Yates correction is 6.8627 with $p$-value $=0.008802$ ).

\section{Discussion}

It is acknowledged that parasitic nematode infection in sharks damage tissues and leave lesions even on their skin. In the current work, whitecheek sharks (Carcharhinus dussumieri) caught in the Arabian Gulf off the coast of Saudi Arabia had skin lesions, manifesting as grey to black irregular lines pertaining to those 


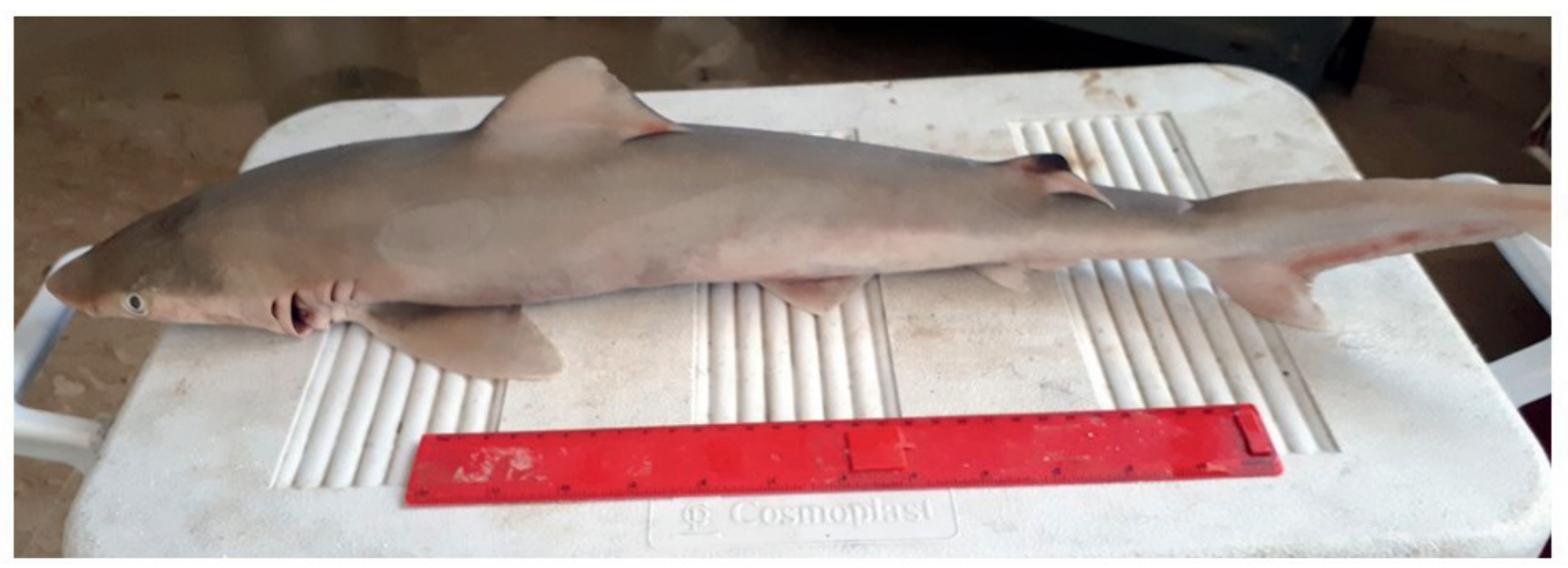

Fig. S1 Supplementary materials

induced by Huffmanela spp. Researchers on this parasite have agreed that specific diagnosis of Huffmanela is mainly based on egg morphology and morphometrics because conspecific adult worms of many species are still not found or described morphologically (Bullard et al., 2012; Ruiz et al., 2013; Justine \& Iwaki, 2014). Therefore, the commonly accepted morphologies used to diagnose Huffmanela spp. pertain mainly to egg length, width and shell shape and texture. In addition, the eggs may have protruding or non-protruding bipolar plugs with the presence or absence of vitelline membrane encapsulating the egg (Moravec, 2001). The diagnosis is usually supported by supplementary data on fish hosts and the egg habitat within the host, for example: the skin, gill arches, muscles, swim bladder, serosa of the intestine and bones (Moravec, 2001; Justine, 2007). According to their characteristics and previously published keys (Bullard et al., 2012; Ruiz et al., 2013; Justine \& Iwaki, 2014), the eggs recovered from the epidermis of the whitecheek shark (Carcharhinus dussumieri) were diagnosed as Huffmanela sp.

The features of the Huffmanela sp. eggs described herein match many aspects with those of other Huffmanela spp., but can be readily differentiated from each other. The dimensions of the eggs overlap the previously reported $H$. carcharhini (Bullard et al., 2012), H. banningi (Moravec \& Campbell, 1991), H. markgracei (Ruiz \& Bullard, 2013) and Huffmanela sp. (Esteves et al., 2009). The eggs resemble those of $H$. carcharhini in being smooth; they have no spines, filaments, ridges or pits in the surface. However, the shell of the $H$. carcharhini egg narrows gradually towards the poles that carry non-protruding plugs (Bullard et al., 2012), while the eggs in this study have obviously protruding polar plugs. The shell surface of $H$. markgracei contained ridges (Ruiz \& Bullard, 2013) and that of $H$. banningi have spines (Moravec \& Campbell, 1991). Finally, the polar eggs of Huffmanela sp. described by Esteves et al. (2009) are much wider $(13.6-22.3 \mu \mathrm{m})$ than those reported here $(4.5-9.5 \mu \mathrm{m})$.

By examining the morphological features of other eggs of Huff- manela sp., we can see that the eggs of $H$. lusitana (Ramos et al., 2019) are easily distinguished from the herein reported Huffmanela sp. by the presence of ridges on its shells. The eggs of H. paronai (Moravec \& Garibaldi, 2000), H. schouteni (Moravec \& Campbell, 1991), H. shikokuensis (Moravec et al., 1998) and H. japonica (Moravec et al., 1998) have the same shell morphology as the currently reported Huffmanela sp. but have different dimensions. The eggs of $H$. mexicana (Moravec \& Fajer-Avila, 2000), H. ossicola (Justine, 2007), H. filamentosa (Justine, 2004), H. longa (Justine, 2007) and H. plectropomi (Justine, 2011) have filamentous shells, while other species have spines, namely the previously mentioned $H$. banningi (Moravec \& Campbell, 1991), $H$. huffmani (Huffman \& Moravec, 1988) and $H$. lata (Ruiz \& Bullard, 2013). Finally, the eggs of $H$. canadensis differ in size from the currently reported Huffmanela sp. and have ridges on the shell (Moravec et al., 2005). Based on these morphological features, eggs of the herein reported Huffmanela sp. can be distinguished from other species by their smooth shells, the characteristic width of the protruding polar plugs, the presence of an outer shell layer near the poles of the eggs and the presence of a wider ring-like structure at the polar ends.

Previously, only a single study had reported the ultrastructure of eggshells of Huffmanela sp., namely $H$. huffmani, using TEM (Zdarska et al., 2001), which showed finer morphological differences than those reported here. While both studies agree that the chitinous layers of the eggs consist of two parts that differ in electron density, the chitinous layers of $H$. huffmani were found to be lamellated in the inner part, while here the chitinous layers were found to be homogenous and non-lamellated. Moreover, the lipid layer reported in this study was homogenous, while in the case of H. huffmani it had a network-like structure.

In the current work, observed lesions due to Huffmanela nematode infection are restricted to the superficial layer of the skin and the lesions were associated with the presence of eggs of Huffmanela sp.. The eggs were not encountered in the underlying muscular 
tissue or internal organs. The lesions in the subcutaneous muscular tissue, like the haemorrhages, oedema and congestion, might be attributed to traumatic injuries that occurred during specimen capture.

A common characteristic of the species described here, $H$. carcharhini (Bullard et al., 2012) and H. lata (Justine, 2005) is that all were found in the skins of the sharks and did not penetrate the internal organs, unlike $H$. markgracei, which inhabited the buccal cavity of an Atlantic sharpnose shark (Ruiz and Bullard, 2013). The current pathological findings resemble previous findings of dermatitis and the presence of black to grey zigzag lines in the superficial layer of the skin induced by $H$. carcharhini eggs in the sandbar shark, without detecting adult parasites in the underlyingmuscular layers (Bullard et al., 2012). The desquamated epithelium of the epidermal cells can be attributed to the presence of eggs and larvae (Moravec \& Garibaldi, 2000).

This is the first report of Huffmanela sp. in Arabian Gulf whitecheek sharks (Carcharhinus dussumieri). This species of shark is native to the Indo-West Pacific Ocean, a huge area extending from the Arabian Sea, along southern continental Asia and reaching south to Australia (Pollerspöck, 2013). Given the prevalence of this parasite in Arabian Gulf whitecheek sharks, it is expected that similar infections are being found in other nearby countries, but are neglected, overlooked or under-reported by inspecting authorities. We lack clear reasoning for the observed marked seasonality of Huffmanela infestation due to the lack of knowledge of the complete life cycle of the species. However, experimental $H$. huffmani infections were established by feeding centrarchid definitive hosts with amphipods infected with second stage larvae (Worsham et al., 2016). Based on that knowledge, the current trend in sharks infected with Huffmanela sp. might be related to the abundance of infected intermediate hosts in the Arabian Gulf. These infections might not be zoonotic, and their effect on the lifestyle and health condition of infected sharks is yet to be explored.

\section{Conflict of Interests}

The authors declare that they have no conflict of interests.

\section{Acknowledgements}

We acknowledge the help and support from fishers in the docking stations, salesmen and workers in the fish markets for their help in sampling. We thank Dr. Omar A. Al-Jabr for revising the manuscript. We extent our thanks for the reviewers who helped in improving the quality of the manuscript. This research did not receive any specific grant from funding agencies in the public, commercial, or not-for-profit sectors.

\section{References}

Attia, M.M., Mahmoud, M.A. \& Ibrahim, M.M. (2021): Morpho- logical and pathological appraisal of Huffmanela sp. (Nematoda: Trichosomoididae) infecting orange-spotted grouper (Epinephelus coioides, Hamilton, 1822) at Jubail Province, Saudi Arabia: a case report. J. Parasit. Dis. https://doi.org/10.1007/s12639-021-01394-x Bullard, S.A., Ruiz, C.F., McElwain, A., MurRay, M.J., Borucinska, J.D., BENZ, G.W. (2012): Huffmanela cf. carcharhini (Nematoda, Trichosomoididae, Huffmanelinae) from skin of a sandbar shark, Carcharhinus plumbeus, in the Pacific Ocean. J. Parasitol., 98: 333 - 340. DOI: $10.1645 / G E-2962.1$

Esteves, A., Seixas, F., Carvalho, S., Nazário, N., Mendes, M., MARTINS, C. (2009): Huffmanela sp. (Nematoda: Trichosomoididae) muscular parasite from Trisopterus luscus captured off the Portuguese coast. Dis. Aquat. Org., 84: 251 - 255. DOI: 10.3354/ da002048

Gállego, J., Riera, C., Portús, M. (1993): Huffmanela sp. eggs (Nematoda: Trichosomoididae), as a human spurious parasite in a child from Barcelona (Spain). Folia Parasitol., 40: 208 - 210

Huffman, D.G., Moravec, F. (1988): First description of adult Huffmanela huffmani Moravec, 1987 (nematode: Trichosomoididae) from the swimbladder of centrarchid fishes of the upper San Marcos River, Central Texas. Folia Parasitol., 35: 227 - 234

Justine, J.L. (2004): Three new species of Huffmanela Moravec, 1987 (Nematoda: Trichosomoididae) from the gills of marine fish off New Caledonia. Syst. Parasitol., 59: 29 - 37. DOI: 10.1023/B:SYPA. $0000038442.25230 .8 \mathrm{~b}$

JustinE, J.L. (2005): Huffmanela lata n. sp. (Nematoda: Trichosomoididae: Huffmanelinae) from the shark Carcharhinus amblyrhynchos (Elasmobranchii: Carcharhinidae) off New Caledonia. Syst. Parasitol., 61: 181 - 184. DOI: 10.1007/s11230-005-3160-8

JustiNE, J.L. (2007): Huffmanela spp. (Nematoda, Trichosomoididae) parasites in coral reef fishes off New Caledonia, with descriptions of $H$. balista n. sp. and $H$. longa n. sp. Zootaxa, 1628: 23 - 41. DOI: $10.5281 /$ zenodo.179332

JustinE, J.L. (2011): Huffmanela plectropomi. sp. (Nematoda: Trichosomoididae: Huffmanelinae) from the coral grouper Plectropomus leopardus (Lacépède) off New Caledonia. Syst. Parasitol., 79: 139 - 143. DOI: 10.1007/s11230-011-9296-9

JustinE, J.L., IWAKI, T. (2014): Huffmanela hamo sp. n. (Nematoda: Trichosomoididae: Huffmanelinae) from the dagger-tooth pike conger Muraenesox cinereus off Japan. Folia Parasitol., 61: 267 271. DOI: $10.14411 / \mathrm{fp} .2014 .029$

Moravec, F. (2001): Trichinelloid Nematodes Parasitic in Cold-Blooded Vertebrates. Academia, Praha, 429 pp.

Moravec, F., Campbell, B.G. (1991): A new Huffmanela species, $H$. schouteni sp. n. (Nematoda, Trichosomoididae), from flying fishes in Curaçao. Folia Parasitol., 38: 29 - 32

Moravec, F., GariBaldi, F. (2000): Huffmanela paronai sp. n. (Nematoda: Trichosomoididae), a new parasite from the skin of swordfish Xiphias gladius in the Ligurian Sea (Western Mediterranean). Folia Parasitol., 47: 309 - 313. DOI: 10.14411/fp.2000.053

Moravec, F., Koudela, B., Ogawa, K., Nagasawa, K. (1998): Two new Huffmanela species, $H$. japonica n. sp. and H. shikokuensis n. sp 
(Nematoda: Trichosomoididae), from marine fishes in Japan. J. Parasitol. 84: 589 - 593

Moravec, F., Fajer-Avila, E. (2000): Huffmanela mexicana n. sp. (Nematoda: Trichosomoididae), from the marine fish Sphoe oides annulatus in Mexico. J. Parasitol., 86: 1229 - 1231. DOI: 10.1645/0022-3395(2000)086[1229:HMNSNT]2.0.CO;2

Moravec, F., Conboy, G.A., Speare, D.J. (2005): A new trichosomoidid from the skin of Sebastes spp. (Pisces) from British Colombia, Canada, J. Parasitol., 91: 411 - 414. DOI: 10.1645/GE-3420

NEWCOMBE, R.G. (1998): Two-sided confidence intervals for the single proportion: comparison of seven methods. Stat. Med. 17: $857-872$

Pollerspöck, J. (2012): Bibliography database of living/fossil sharks, rays and chimaeras (Chondrichtyes: Elasmobranchii, Holocephali) - Host - Parasites List -, www.shark-references.com, World Wide Web electronic publication, Version 08/2012.

Pollerspöck, J. (2013): Carcharhinus dussumieri. Catalogue of Fishes. SharkReference.com. Retrieved 2013-10-08.

Ramos, P., Carvalho, R., Rosa, F., Alexandre-Pires, G., Seixas, F., Esteves, A., Huffman, D. (2019): Huffmanela lusitana sp. n. (Nematoda: Trichosomoididae) infecting pouting, Trisopterus luscus (Teleostei: Gadidae) off the Atlantic coast of Portugal. Int. J. Parasitol. Parasites Wildl., 9: 266 - 273. DOI:10.1016/j.jppaw.2019.05.010 RoBeRTS, R. (2012): Fish Pathology. Fourth Edition. pp. 383 - 401. DOI: 10.1002/9781118222942.ch9
Ruiz, C.F., Bullard, S.A. (2013): Huffmanela markgracei sp. n. (Nematoda: Trichosomoididae) from buccal cavity of Atlantic sharpnose shark, Rhizoprionodon terraenovae (Carcharhiniformes: carcharhinidae), in the northwestern Gulf of México off Texas. Folia Parasitol., 60: 353 - 358. DOI: 10.14411/fp.2013.036 Ruiz, C.F., Ray, C.L., Cook, M., Grace, M.A., Bullard, S.A. (2013): A new species of Trichosomoididae (Nematoda) from skin of red snapper, Lutjanus campechanus (Perciformes: Lutjanidae), on the Texas-Louisiana shelf, northern Gulf of Mexico. J. Parasitol., 99: 318 - 326. DOI: 10.1645/GE-3249.1

Schouten, H., Suriel-Smeets, R.M., KibBelaar, M.A. (1968): The simultaneous occurrence of ova resembling Dicrocoelium dendriticum or Capillaria hepatica in the stools of inhabitants of Curaçao. Trop. Geogr. Med., 20: $271-275$

Worsham, M.L.D., Huffman, D.G., Moravec, F., Gibson, J.R. (2016): The life cycle of Huffmanela huffmani Moravec, 1987 (Nematoda: Trichosomoididae), an endemic marine-relict parasite of Centrarchidae from a Central Texas spring. Folia Parasitol., 63: 020. DOI: 10.14411/fp.2016.020

YATES, F. (1934): Contingency table involving small numbers and the $\chi 2$ test. J. Roy. Stat. Soc. Suppl., 1, $217-235$.

Zdarska, Z., Huffman, D.G., Moravec, F., Nebesarova, J. (2001): Egg shell ultrastructure of the fish nematode Huffmanela huffmani (Trichosomoididae). Folia Parasitol., 48: 231 - 234. DOI:10.14411/ fp.2001.038 